OPEN ACCESS

Edited by:

Carlos Suarez,

University of Oviedo, Spain

Reviewed by:

Hua Chen,

University of Miami,

United States

Gianluca Baldanzi,

Università degli Studi del Piemonte

Orientale, Italy

${ }^{*}$ Correspondence:

Song-Bo Fu

fusb@lzu.edu.cn

Specialty section:

This article was submitted to

Cancer Endocrinology,

a section of the journal

Frontiers in Endocrinology

Received: 24 March 2021

Accepted: 24 May 2021

Published: 08 June 2021

Citation:

Ma C-X, Ma X-N, Li Y-D and Fu S-B (2021) The Role of Primary Cilia in

Thyroid Cancer: From Basic Research to Clinical Applications.

Front. Endocrinol. 12:685228. doi: 10.3389/fendo.2021.685228

\section{The Role of Primary Cilia in Thyroid Cancer: From Basic Research to Clinical Applications}

\author{
Cheng-Xu Ma ${ }^{1,2}$, Xiao-Ni Ma ${ }^{1,2}$, Ying-Dong $\mathrm{Li}^{3}$ and Song-Bo Fu ${ }^{1,2 *}$ \\ ${ }^{1}$ Department of Endocrinology, The First Hospital of Lanzhou University, Lanzhou, China, ${ }^{2}$ The First Clinical Medical College \\ of Lanzhou University, Lanzhou, China, ${ }^{3}$ College of Integrated Traditional Chinese and Western Medicine, Gansu University \\ of Chinese Medicine, Lanzhou, China
}

Primary cilia (PC) are microtubule-based organelles that are present on nearly all thyroid follicle cells and play an important role in physiological development and in maintaining the dynamic homeostasis of thyroid follicles. PC are generally lost in many thyroid cancers (TCs), and this loss has been linked to the malignant transformation of thyrocytes, which is regulated by PC-mediated signaling reciprocity between the stroma and cancer cells. Restoring PC on TC cells is a possible promising therapeutic strategy, and the therapeutic response and prognosis of TC are associated with the presence or absence of PC. This review mainly discusses the role of PC in the normal thyroid and TC as well as their potential clinical utility.

Keywords: primary cilium, thyroid cancer, cell cycle, ciliogenesis, therapeutic strategy

\section{INTRODUCTION}

Primary cilia (PC) are solitary, nonmotile microtubule-based organelles that project from the cell surface and function similar to an antenna on the cell to sense and convey multiple extracellular signals (1). In thyroid follicular epithelial cells, PC protrude from the apical surface into the follicular luminal space, where they may sense the follicular luminal environment and transmit signals to follicular epithelial cells to maintain follicular homeostasis (2). Existing data have revealed that many signaling pathways important for development and disease, including the Hedgehog (Hh), Wnt, and platelet-derived growth factor (PDGF) pathways, are localized to PC (3). Therefore, a loss of PC is associated with the onset of malignancy in some human tumors.

Thyroid cancer (TC) is the most common endocrine cancer and has a rapidly increasing incidence but relatively stable mortality. The main histological subtypes of TC are papillary thyroid cancer (PTC), follicular thyroid cancer (FTC), poorly differentiated thyroid cancer (PDTC), anaplastic thyroid cancer (ATC), and medullary thyroid cancer (MTC). The first four types originate from thyroid follicular epithelial cells, and MTC arises from thyroid parafollicular cells. PC is well preserved in PTC and FTC, and their frequency and length appear similar to those of normal thyroid follicles. Interestingly, defects in PC genesis have been observed in ATC (4). Additionally, oncogenic alterations, coupled to specific intracellular downstream signaling pathways, lead to the development of different subtypes of TC. PC as a mediator of these signaling pathways regulates TC development. Alteration in PC influences the communication 
between TC cells and the tumor microenvironment, which in turn affected the therapeutic response and prognosis of TC.

In this review, we briefly describe the formation and structure of PC on thyroid follicular cells and explore the potential roles of $\mathrm{PC}$ in maintaining cellular homeostasis and promoting the progression of thyroid disease.

\section{STRUCTURE OF PC IN THE NORMAL HUMAN THYROID GLAND}

PC consist of the basal body, transition zone and axoneme. The basal body derived from the mother centriole of the centrosome that is composed of nine microtubule triplets (5). The axoneme is constructed from nine parallel microtubule doublets protruding from the mother centriole, which anchors the PC within the plasma membrane. The transition zone is a specialized ciliary domain that connects the basal body and axoneme backbone, which is localized toward the membrane in a Y-shaped arrangement known as the "ciliary gate." This gate separates proteins inside the PC from proteins in the cytoplasm and limits extracellular signal transduction.

In human thyroid follicular cells, $\mathrm{PC}$ are present in a ringshaped $9+0$ axonemal configuration, and the microtubules and diameters of PC steadily decrease toward the distal end of the cilia while becoming broader closer to the base of the cilium. Dynein arms and central pair microtubules are absent (6). Therefore, PC are non-motile structures. The length of PC ranges between 5.0 and $10.7 \mu \mathrm{m}$, and the mean length is $7.3 \pm$ $1.2 \mu \mathrm{m}$ (7). Almost all human thyroid follicular cells displays at least one PC that protrudes from the apical surface into the follicular lumen, and occasionally, the presence of two PC in a Vshaped distribution has been observed on adjacent cells. The PC of thyroid follicular cells taking advantage of their ideal localization coupled to specific intracellular downstream signaling pathways regulates thyroid development.

\section{ABNORMAL LENGTH AND FREQUENCY OF PC IN TC}

The frequency and length of PC often change when they respond to diverse stimuli from both inside and outside of thyrocytes. In $\mathrm{TC}$, the distribution and frequency of PC are aberrantly changed, the number of thyrocytes exhibiting one or more cilia steadily decreases from ordinary PTC to FTC, and FTC, PDTC, and ATC usually lack cilia (8). However, conventional PTC and follicular variants of PTC display well-expressed PC, the length of PC is strikingly increased, and the frequency of PC seems to be unchanged compared with normal thyroid glands, only oncocytic variants of PTC have a decreased frequency and length of PC (9). More importantly, these variations of PC appear to be associated with the progression and prognosis of TC. Moreover, the pathogenicity of PC variations in the experimental animals of thyroid gland was also observed. A mouse model lacking PC showed normal folliculogenesis and hormonogenesis at ages of less than 7 weeks. After that, thyroid follicles became irregularly dilated and destroyed and displayed malignant properties (papillary or solid proliferative nodules), papillary or solid hyperplastic nodules were considered PDTC (2), and other types of TC were not observed.

In cell level, the frequency of PC is not different between human normal thyroid follicular cells and PTC cell lines, but the frequency of PC is significantly reduced in ATC cell lines (2). The loss of PC on ATC cells was associated with TC tumorigenesis and progression (10). However, a study from Junguee Lee et al. demonstrated that loss of PC in PTCs results in increased apoptosis, and it is associated with reduced tumor aggressiveness (4). In this context, the loss of PC appears to select TC cells with more malignant features. These discrepant conclusions require further confirmation due to the use of different research models.

In conclusion, some possible mechanisms for the association with PC abnormal changes and TC tumorigenesis have been proposed (Figure 1). So the loss of PC is at least partially associated with the tumorigenesis and progression of TC.

\section{PC MEDIATE HH, MAPK, AND PI3K SIGNALING IN TC}

Some signaling pathways related to the occurrence, development, invasion, and metastasis of TC are mediated by PC, and the receptors for these signaling pathways are often localized to PC. In the presence of $\mathrm{Hh}, \mathrm{Ptch} 1$ is transported out of the cilium, and Smo is transported into the cilium, where it promotes the formation of the activator form of Gli. Gli protein levels increase in the cilium, and Gli proteins are then transported out of the cilium and into the nucleus, where they activate $\mathrm{Hh}$ target genes. In the absence of $\mathrm{Hh}, \mathrm{Ptch} 1$ is localized to the ciliary membrane, Smo is excluded from the cilium, and Gli is converted to its repressor form (11). At an early phase of TC development, TC stroma secreted Hh ligand mediates tumorstroma interaction and $\mathrm{Hh}$ pathway are aberrantly activated, which supports TC cell invasion, migration, and growth in nonadherent conditions (12). Additionally, PC provide a spatially diverse platform for mediating interaction between the stroma and cancer cells, so PC genesis defects may disturb this interaction mediating $\mathrm{Hh}$ pathway aberrant activation. These data show that the PC-mediated $\mathrm{Hh}$ pathway participates in TC tumorigenesis.

On the other hand, PC-mediated growth factor binding to RTKs triggers the MAPK and PI3K-AKT cascades to regulate TC cell proliferation, and elevated RTK activity also promotes RET/ RAS/BRAF mutations $(13,14)$. Moreover, oncogenic RAS/BRAF/ MEK pathway influences Hh pathway activation in TC cell, generating a ligand independent non-canonical mechanism of activation.

Since PC are the carrier of these signaling proteins, and they integrate Hh and RTK signaling crosstalk to coordinate thyroid hormone synthesis and development. Changes of PC directly affect these related pathways, which is associated with tumorigenesis and TC development. 


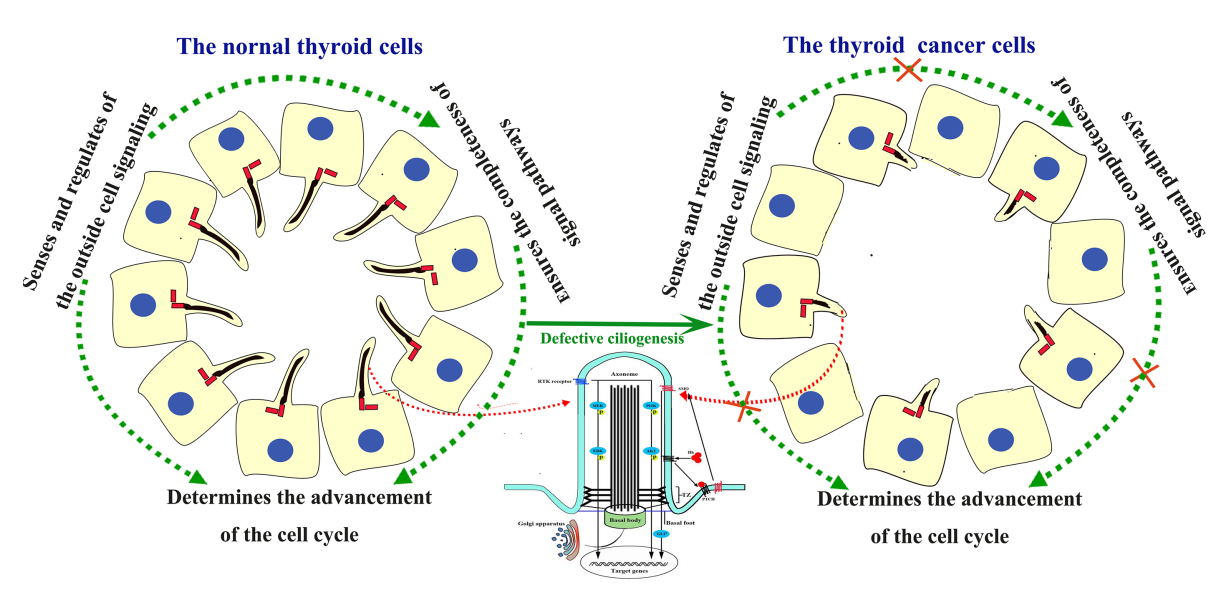

FIGURE 1 | Structure of the PC and signaling pathways involving cilia in the human thyroid gland and TC. In normal thyroid gland cells, the PC acts as the sensor and regulator of the outside cell signaling. In TC cells, the PC was absent. Absence of the PC block the signal from outside and neighbors, and disturb the signal pathways inside cells, thus lead to uncontrolled cell cycle process and tumorigenesis.

\section{PC PROTRUSION AND RESORPTION AFFECT TC CELL FATE}

PC protrusion and resorption are tightly coordinated with the cell cycle; in addition, the coupling of both ciliogenesis and the cell cycle depends on the centrosome, and the role of the centrosome shifts from cell division to ciliogenesis (15). Cells become quiescent, or proliferating cells enter G1 phase (16), the centrioles from the centrosome begin to migrate to the cell surface and subsequently form the basal body, and assembly of PC is initiated; the PC then extend from the basal body into the follicular lumen. In dividing cells, PC are resorbed before S phase or during G2 phase (17). Subsequently, the centrosome forms the mitotic spindle, and the cell enters mitosis. After mitosis, centrosomes are again available to assemble PC, either in G0 or in early G1 phase (18). Utrilla confirmed this process in thyroid cells (7). These findings suggest that ciliogenesis and the cell cycle appear to regulate each other via mutual crosstalk.

\section{PC PROTEINS AFFECT TC PROGRESSION}

PC proteins related to Aurora kinase A, NIMA-related kinases (Nek), Polo-like kinase (Plk1), and spermatogenesis-associated protein 4 (Spata4) have been identified as critical for the regulation of both cilia and the cell cycle. Aurora kinase A, which is localized to the centrosome and radial microtubules in PC (19), is highly or weakly expressed in TC tissues and cell lines, and this abnormal expression induces thyrocyte malignant transformation. Moreover, activation of Aurora kinase A in late G2 phase triggers spindle assembly and PC disassembly, and it becomes inactivated at the completion of mitosis. Overexpression of Aurora kinase A generally implies a poor prognosis and is a new molecular target in TC therapy (20). Nek, which is localized to PC and centrosomes, inhibits ciliogenesis and promotes spindle assembly, and it may contribute to the coordination between ciliogenesis and cell cycle progression (21). Overexpression of Nek 1 in classical and follicular variants of PTC has a high specificity and sensitivity and is often related to aggressiveness. Therefore, Nek 1 may contribute to the identification of malignant features during TC diagnosis (22). Plk1, which is localized to the transition zone of PC, rapidly evokes PC resorption and regulates cell cycle progression at the G2-M phase transition $(23,24)$. Plk1 expression is only occasionally observed in normal thyrocytes, but overexpression of Plk1 is more frequently detected in smaller PTCs, microcarcinomas, and incidental carcinomas. Overexpression of Plk1 may be an early event in PTC progression (25). Spata4 is a spermatogenesis-associated protein associated with thyroid hormone in fish (26), and spata 4 knockdown leads to an arrest of cells in S phase and causes a decrease in the number of cilia in human retinal epithelial cells (27). The orderly regulation of these PC proteins between ciliogenesis and the cell cycle determines the survival of TC cells.

We focused on how PC proteins are linked to cell cycle progression and ciliogenesis in TC. Although the mechanisms by which TC cells lose their cilia are unknown, Aurora kinase A, Nek, Plk1, and Spata 4 are associated with cilium disassembly and cell cycle regulation.

\section{DRUGS WITH EFFECTS ON PC}

The effects of drugs on PC in human cell lines and experimental animal models of TC have not been identified, but U0126 inhibits the elongation of cilia, ganetespib causes the loss of PC in experimental animal models of other diseases $(28,29)$. 
Additionally, the administration of U0126 and ganetespib effectively inhibits the proliferation of different histological types of TC cells $(30,31)$. Evidence for the association of U0126 and ganetespib with PC should be investigated in TC.

Drugs targeting PC have been assessed in patients with TC, and the findings from clinical trials show that doxorubicin, paclitaxel and docetaxel have modest antitumor activity in patients with advanced, nonmedullary TC (32). Carboplatin is recommended as a treatment for ATC in clinical practice guidelines in oncology (33). The administration of these drugs for TC may provide a clinical benefit in adjuvant settings. Doxorubicin induces cilium formation in breast fibroblasts (34), paclitaxel causes cilium elongation in the quail oviduct (35), and docetaxel decreases cilia numbers in olfactory cells (36). In addition, carboplatin induces PC disassembly in sensory cells (37) and has been used to treat TC. Some RTK inhibitors have been recently approved for use in clinical practice, namely sorafenib and lenvatinib, have been approved for differentiated thyroid cancer (DTC) and PDTC, and vandetanib and cabozantinib have been approved for MTC (38), but their effect on PC has not been reported.

Anticancer drugs with documented effects on PC have been proposed. These drugs induce PC disassembly, restore ciliogenesis, lengthen $\mathrm{PC}$, and prevent the accumulation of Smo in PC. They have been assessed in TC in preclinical and clinical studies, considering these factors will formulate rational therapeutic strategies for TC.

\section{IS RESTORING CILIA A PROMISING THERAPEUTIC STRATEGY IN TC CELLS?}

Although controversy exists regarding whether the length of PC is modified in PTC, the frequency of PC in TC cells is usually decreased. In addition, ATC and MTC exhibit loss of PC, and dysfunction of PC in TC cells is associated with tumorigenesis and malignancy. More importantly, in Hh pathway-dependent cancers, there is loss of PC as a mechanism of resistance to Smo inhibitors (39). Accordingly, restoring cilia may be a promising therapeutic strategy in TC (40).

There have been some pre-clinical examples of restoration of $\mathrm{PC}$ as a therapeutic target, such as restoration of PC by HDAC inhibitors in cholangiocarcinoma reduce cholangiocarcinoma cell growth (41-43). In addition, the use of HDAC inhibitors to treat TC has been well described, although they failed to trigger a major response against PTC, ATC, and MTC in clinical trials, HDAC inhibitors produced encouraging results in PTC, ATC, and MTC cell lines (44-46). Compounds (gefitinib and dexamethasone) that are able to restore cilia have been verified in cell lines of multiple human cancers (such as pancreatic, kidney, breast, and lung cancers) (47). Gefitinib shows limited effectiveness in patients with advanced TC (48), and dexamethasone exerts antiproliferative effects on a human MTC cell line (49).

It is hard to say that the restoring of cilia by those drugs was a primary effect or a secondary effect. However, several drugs with effects on PC have been tested in different human cell lines of TC, which indicate a possible application of these drugs in clinical studies. Future studies are required to evaluate the effects of these drugs on PC of TC.

\section{CONCLUSIONS AND FUTURE PROSPECTS}

Based on the findings described above, PC play a role in sustaining thyroid follicular cell polarity, differentiation, and proliferation and feature signaling pathways associated with TC. PC undergo cycles of assembly and disassembly that control TC cell survival, and PC loss in TC cells is usually linked to tumor aggressiveness in the clinic. PC in thyroid cells appear to function as tumor suppressors, and treatments that restore PC may be a potentially promising therapeutic strategy for TC. Preclinical and clinical studies will be required to test the roles of PC in the occurrence and progression of TC.

In the future, the relationship between ciliogenesis and pathological differentiation of $\mathrm{TC}$ tissue should receive increasing attention. Studies of the effects of potential oncogenic genetic mutations on PC formation may further reveal the mechanisms underlying TC pathogenesis, and powerful omics analyses have the potential to provide key insights into the role of PC in TC. Therefore, larger studies are required to assess whether the absence of $\mathrm{PC}$ drives $\mathrm{TC}$ transformation or is a secondary effect of tumorigenesis, which will be critical when considering ciliotherapy as a potential strategy.

\section{AUTHOR CONTRIBUTIONS}

C-XM, X-NM, Y-dL, and S-BF conceived the study and wrote the paper. All authors contributed to the article and approved the submitted version.

\section{FUNDING}

The author(s) disclose receipt of the following forms of financial support for the research, authorship, and publication of this article: this work was supported by grants from the Construction Program of Gansu Provincial Clinical Medical Research Center for Endocrine Diseases (20JR10FA667), The Gansu Provincial Natural Science Foundation (20JR10RA681), The Lanzhou Chengguan District Science and Technology Plan Project (2019SHFZ0038), and The Special Funds of Science and Technology Development of the Chinese Central Government to guide Local in 2020 (1004TCYA032). 


\section{REFERENCES}

1. Singla V, Reiter JF. The Primary Cilium as the Cell's Antenna: Signaling at a Sensory Organelle. Science (2006) 313(5787):629-33. doi: 10.1126/science.1124534

2. Lee J, Yi S, Chang JY, Kim JT, Sul HJ, Park KC, et al. Loss of Primary Cilia Results in the Development of Cancer in the Murine Thyroid Gland. Mol Cells (2019) 42(2):113-22. doi: 10.14348/molcells.2018.0430

3. Jenks AD, Vyse S, Wong JP, Kostaras E, Keller D, Burgoyne T, et al. Primary Cilia Mediate Diverse Kinase Inhibitor Resistance Mechanisms in Cancer. Cell Rep (2018) 23(10):3042-55. doi: 10.1016/j.celrep.2018.05.016

4. Lee J, Park KC, Sul HJ, Hong HJ, Kim KH, Kero J, et al. Loss of Primary Cilia Promotes Mitochondria-Dependent Apoptosis in Thyroid Cancer. Sci Rep (2021) 11(1):4181. doi: 10.1038/s41598-021-83418-3

5. Hua K, Ferland RJ. Primary Cilia Proteins: Ciliary and Extraciliary Sites and Functions. Cell Mol Life Sci (2018) 75(9):1521-40. doi: 10.1007/s00018-0172740-5

6. Martin A, Hedinger C, Häberlin-Jakob M, Walt H. Structure and Motility of Primary Cilia in the Follicular Epithelium of the Human Thyroid. Virchows Archiv B Cell Pathol including Mol Pathol (1988) 55(3):159-66. doi: 10.1007/ bf02896572

7. Utrilla JC, Gordillo-Martínez F, Gómez-Pascual A, Fernández-Santos JM, Garnacho C, Vázquez-Román V, et al. Comparative Study of the Primary Cilia in Thyrocytes of Adult Mammals. J Anat (2015) 227(4):550-60. doi: $10.1111 /$ joa. 12360

8. Nesland JM, Sobrinho-Simoes M, Johannessen JV. Scanning Electron Microscopy of the Human Thyroid Gland and Its Disorders. Scanning microscopy (1987) 1(4):1797-810.

9. Lee J, Yi S, Kang YE, Chang JY, Kim JT, Sul HJ, et al. Defective Ciliogenesis in Thyroid Hürthle Cell Tumors Is Associated With Increased Autophagy. Oncotarget (2016) 7(48):79117-30. doi: 10.18632/oncotarget.12997

10. Lee J, Yi S, Won M, Song YS, Yi HS, Park YJ, et al. Loss-of-Function of IFT88 Determines Metabolic Phenotypes in Thyroid Cancer. Oncogene (2018) 37 (32):4455-74. doi: 10.1038/s41388-018-0211-6

11. Hassounah NB, Bunch TA, McDermott KM. Molecular Pathways: The Role of Primary Cilia in Cancer Progression and Therapeutics With a Focus on Hedgehog Signaling. Clin Cancer Res (2012) 18(9):2429-35. doi: 10.1158/ 1078-0432.ccr-11-0755

12. Xu X, Ding H, Rao G, Arora S, Saclarides CP, Esparaz J, et al. Activation of the Sonic Hedgehog Pathway in Thyroid Neoplasms and Its Potential Role in Tumor Cell Proliferation. Endocrine-related Cancer (2012) 19(2):167-79. doi: 10.1530/erc-11-0305

13. Abdullah MI, Junit SM, Ng KL, Jayapalan JJ, Karikalan B, Hashim OH. Papillary Thyroid Cancer: Genetic Alterations and Molecular Biomarker Investigations. Int J Med Sci (2019) 16(3):450-60. doi: 10.7150/ijms.29935

14. Christensen ST, Morthorst SK, Mogensen JB, Pedersen LB. Primary Cilia and Coordination of Receptor Tyrosine Kinase (RTK) and Transforming Growth Factor $\beta$ (Tgf- $\beta$ ) Signaling. Cold Spring Harb Perspect Biol (2017) 9(6): a028167. doi: 10.1101/cshperspect.a028167

15. Pan J, Snell W. The Primary Cilium: Keeper of the Key to Cell Division. Cell (2007) 129(7):1255-7. doi: 10.1016/j.cell.2007.06.018

16. Dawe HR, Farr H, Gull K. Centriole/Basal Body Morphogenesis and Migration During Ciliogenesis in Animal Cells. J Cell Sci (2007) 120(Pt 1):7-15. doi: $10.1242 /$ jcs.03305

17. Avasthi P, Marshall WF. Stages of Ciliogenesis and Regulation of Ciliary Length. Differentiation; Res Biol Diversity (2012) 83(2):S30-42. doi: 10.1016/ j.diff.2011.11.015

18. Sánchez I, Dynlacht BD. Cilium Assembly and Disassembly. Nat Cell Biol (2016) 18(7):711-7. doi: 10.1038/ncb3370

19. Bischoff JR, Anderson L, Zhu Y, Mossie K, Ng L, Souza B, et al. A Homologue of Drosophila Aurora Kinase Is Oncogenic and Amplified in Human Colorectal Cancers. EMBO J (1998) 17(11):3052-65. doi: 10.1093/emboj/17.11.3052

20. Baldini E, Sorrenti S, D’Armiento E, Prinzi N, Guaitoli E, Favoriti P, et al. Aurora Kinases: New Molecular Targets in Thyroid Cancer Therapy. La Clinica Terapeutica (2012) 163(6):e457-62.

21. Mahjoub MR, Trapp ML, Quarmby LM. Nima-Related Kinases Defective in Murine Models of Polycystic Kidney Diseases Localize to Primary Cilia and Centrosomes. J Am Soc Nephrol JASN (2005) 16(12):3485-9. doi: 10.1681/ asn.2005080824
22. Melo-Hanchuk TD, Martins MB, Cunha LL, Soares FA, Ward LS, Vassallo J, et al. Expression of the NEK Family in Normal and Cancer Tissue: An Immunohistochemical Study. BMC Cancer (2020) 20(1):23. doi: 10.1186/ s12885-019-6408-4

23. Seeger-Nukpezah T, Liebau MC, Höpker K, Lamkemeyer T, Benzing T, Golemis EA, et al. The Centrosomal Kinase Plk1 Localizes to the Transition Zone of Primary Cilia and Induces Phosphorylation of Nephrocystin-1. PloS One (2012) 7(6):e38838. doi: 10.1371/journal.pone.0038838

24. Ito Y, Yoshida H, Matsuzuka F, Matsuura N, Nakamura Y, Nakamine H, et al. Polo-Like Kinase 1 (PLK1) Expression Is Associated With Cell Proliferative Activity and Cdc2 Expression in Malignant Lymphoma of the Thyroid. Anticancer Res (2004) 24(1):259-63.

25. Ito Y, Miyoshi E, Sasaki N, Kakudo K, Yoshida H, Tomoda C, et al. Polo-Like Kinase 1 Overexpression Is an Early Event in the Progression of Papillary Carcinoma. Br J Cancer (2004) 90(2) 414-8. doi: 10.1038/sj.bjc.6601540

26. Li W, Zhu L, Zha J, Wang Z. Effects of Decabromodiphenyl Ether (Bde-209) on Mrna Transcription of Thyroid Hormone Pathway and Spermatogenesis Associated Genes in Chinese Rare Minnow (Gobiocypris Rarus). Environ Toxicol (2014) 29(1):1-9. doi: 10.1002/tox.20767

27. Albee AJ, Kwan AL, Lin H, Granas D, Stormo GD, Dutcher SK. Identification of Cilia Genes That Affect Cell-Cycle Progression Using Whole-Genome Transcriptome Analysis in Chlamydomonas Reinhardtti. G3 (Bethesda Md) (2013) 3(6):979-91. doi: 10.1534/g3.113.006338

28. Kim JI, Kim J, Jang HS, Noh MR, Lipschutz JH, Park KM. Reduction of Oxidative Stress During Recovery Accelerates Normalization of Primary Cilia Length That Is Altered After Ischemic Injury in Murine Kidneys. Am J Physiol Renal Physiol (2013) 304(10):F1283-94. doi: 10.1152/ajprenal.00427.2012

29. Nikonova AS, Deneka AY, Kiseleva AA, Korobeynikov V, Gaponova A, Serebriiskii IG, et al. Ganetespib Limits Ciliation and Cystogenesis in Autosomal-Dominant Polycystic Kidney Disease (ADPKD). FASEB J (2018) 32(5):2735-46. doi: 10.1096/fj.201700909R

30. Kim JB, Yang EY, Woo J, Kwon H, Lim W, Moon BI. Sodium Selenite Enhanced the Anti-Proliferative Effect of MEK-ERK Inhibitor in Thyroid Cancer Cells. In Vivo (2020) 34(1):185-90. doi: 10.21873/invivo.11760

31. Lin SF, Lin JD, Hsueh C, Chou TC, Yeh CN, Chen MH, et al. Efficacy of an HSP90 Inhibitor, Ganetespib, in Preclinical Thyroid Cancer Models. Oncotarget (2017) 8(25):41294-304. doi: 10.18632/oncotarget.17180

32. Bible KC, Kebebew E, Brierley J, Brito JP, Cabanillas ME, Clark TJ Jr, et al. 2021 American Thyroid Association Guidelines for Management of Patients With Anaplastic Thyroid Cancer. Thyroid (2021) 31(3):337-86. doi: 10.1089/ thy.2020.0944

33. Haddad RI, Lydiatt WM, Ball DW, Busaidy NL, Byrd D, Callender G, et al. Anaplastic Thyroid Carcinoma, Version 2.2015. J Natl Compr Canc Netw (2015) 13(9):1140-50. doi: 10.6004/jnccn.2015.0139

34. Filipová A, Diaz Garcia D, Bezrouk A, Ćúzková D, Dvořák J, Filip S. The Toxic Effect of Cytostatics on Primary Cilia Frequency and Multiciliation. J Cell Mol Med (2019) 23(8):5728-36. doi: 10.1111/jcmm.14487

35. Boisvieux-Ulrich E, Laine MC, Sandoz D. In Vitro Effects of Taxol on Ciliogenesis in Quail Oviduct. J Cell Sci (1989) 92( Pt 1):(9-20. doi: 10.1242/jcs.92.1.9

36. Kavoi BM, Plendl J, Makanya AN, Ochieng S, Kiama SG. Effects of Anticancer Drug Docetaxel on the Structure and Function of the Rabbit Olfactory Mucosa. Tissue Cell (2014) 46(3):213-24. doi: 10.1016/j.tice. 2014.04.005

37. Mount RJ, Takeno S, Wake M, Harrison RV. Carboplatin Ototoxicity in the Chinchilla: Lesions of the Vestibular Sensory Epithelium. Acta Otolaryngol Suppl (1995) 519:60-5. doi: 10.3109/00016489509121871

38. Viola D, Valerio L, Molinaro E, Agate L, Bottici V, Biagini A, et al. Treatment of Advanced Thyroid Cancer With Targeted Therapies: Ten Years of Experience. Endocrine-related Cancer (2016) 23(4):R185-205. doi: 10.1530/ erc-15-0555

39. Zhao X, Pak E, Ornell KJ, Pazyra-Murphy MF, MacKenzie EL, Chadwick EJ, et al. A Transposon Screen Identifies Loss of Primary Cilia as a Mechanism of Resistance to SMO Inhibitors. Cancer Discov (2017) 7(12):1436-49. doi: 10.1158/2159-8290.cd-17-0281

40. Peixoto E, Richard S, Pant K, Biswas A, Gradilone SA. The Primary Cilium: Its Role as a Tumor Suppressor Organelle. Biochem Pharmacol (2020) 175:113906. doi: 10.1016/j.bcp.2020.113906 
41. Gradilone SA, Radtke BN, Bogert PS, Huang BQ, Gajdos GB, LaRusso NF. Hdac6 Inhibition Restores Ciliary Expression and Decreases Tumor Growth. Cancer Res (2013) 73(7):2259-70. doi: 10.1158/0008-5472. CAN-12-2938

42. Gradilone SA, Pisarello MJL, LaRusso NF. Primary Cilia in Tumor Biology: The Primary Cilium as a Therapeutic Target in Cholangiocarcinoma. Curr Drug Targets (2017) 18(8):958-63. doi: 10.2174/1389450116666150223162737

43. Mansini AP, Lorenzo Pisarello MJ, Thelen KM, Cruz-Reyes M, Peixoto E, Jin S, et al. MicroRNA (miR)-433 and Mir-22 Dysregulations Induce HistoneDeacetylase-6 Overexpression and Ciliary Loss in Cholangiocarcinoma. Hepatology (2018) 68(2):561-73. doi: 10.1002/hep.29832

44. Spartalis E, Athanasiadis DI, Chrysikos D, Spartalis M, Boutzios G, Schizas D, et al. Histone Deacetylase Inhibitors and Anaplastic Thyroid Carcinoma. Anticancer Res (2019) 39(3):1119-27. doi: 10.21873/anticanres.13220

45. Damaskos C, Garmpis N, Valsami S, Spartalis E, Antoniou EA, Tomos P, et al. Histone Deacetylase Inhibitors: A Novel Therapeutic Weapon Against Medullary Thyroid Cancer? Anticancer Res (2016) 36(10) 5019-24. doi: 10.21873 /anticanres.11070

46. Spartalis E, Kotrotsios K, Chrysikos D, Spartalis M, Paschou SA, Schizas D, et al. Histone Deacetylase Inhibitors and Papillary Thyroid Cancer. Curr Pharm Des (2020) 27:2199-208. doi: 10.2174/1381612826666201211112234
47. Khan NA, Willemarck N, Talebi A, Marchand A, Binda MM, Dehairs J, et al. Identification of Drugs That Restore Primary Cilium Expression in Cancer Cells. Oncotarget (2016) 7(9):9975-92. doi: 10.18632/oncotarget.7198

48. Pennell NA, Daniels GH, Haddad RI, Ross DS, Evans T, Wirth LJ, et al. A Phase II Study of Gefitinib in Patients With Advanced Thyroid Cancer. Thyroid (2008) 18(3):317-23. doi: 10.1089/thy.2007.0120

49. Chung YJ, Lee JI, Chong S, Seok JW, Park SJ, Jang HW, et al. AntiProliferative Effect and Action Mechanism of Dexamethasone in Human Medullary Thyroid Cancer Cell Line. Endocr Res (2011) 36(4):149-57. doi: $10.3109 / 07435800.2011 .593012$

Conflict of Interest: The authors declare that the research was conducted in the absence of any commercial or financial relationships that could be construed as a potential conflict of interest.

Copyright (C) $2021 \mathrm{Ma}, \mathrm{Ma}, \mathrm{Li}$ and $\mathrm{Fu}$. This is an open-access article distributed under the terms of the Creative Commons Attribution License (CC BY). The use, distribution or reproduction in other forums is permitted, provided the original author(s) and the copyright owner(s) are credited and that the original publication in this journal is cited, in accordance with accepted academic practice. No use, distribution or reproduction is permitted which does not comply with these terms. 